\title{
Isolation of a human betaretrovirus resembling mouse mammary tumor virus (MMTV) from patients with primary biliary cirrhosis Stan Indik ${ }^{1}$, Anahita Mojiri², Isabella Wong${ }^{2}$, Guangzhi Zhang2, Shawn Wasilenko² and Andrew Mason*2
}

\author{
Address: ${ }^{1}$ Department of Virology, University of Veterinary Medicine, Vienna, A-1210, Austria and ${ }^{2}$ Department of Medicine, University of Alberta, \\ Edmonton, AB, T6G 2X8, Canada \\ * Corresponding author
}

from Frontiers of Retrovirology: Complex retroviruses, retroelements and their hosts

Montpellier, France. 21-23 September 2009

Published: 24 September 2009

Retrovirology 2009, 6(Suppl 2):P55 doi:10.1 I86/I742-4690-6-S2-P55

This abstract is available from: http://www.retrovirology.com/content/6/S2/P55

(c) 2009 Indik et al; licensee BioMed Central Ltd.

\section{Background}

A human betaretrovirus resembling the MMTV has been cloned from biliary epithelial cells and perihepatic lymph nodes of patients with primary biliary cirrhosis (PBC) [1]. The human betaretrovirus can trigger a PBC specific phenotype in vitro and antiviral therapy improves both biochemical and histological disease in patients with PBC. The human betaretrovirus can be detected in perihepatic lymph nodes in $75 \%$ of PBC patients by immunochemistry and RT-PCR [1]. Our goal was to provide proof that a human betaretrovirus infects patients by isolating the human betaretrovirus and detecting viral integration sites.

\section{Methods}

DNA from livers, biliary epithelium and lymph nodes was used to identify proviral integration sites using linker mediated PCR. PBC peri-hepatic lymph node homogenates were co-cultured with Hs578T cells and infected cells were subcloned, clonally expanded and tested for betaretrovirus infection.

\section{Results}

Betaretrovirus was detected by RT-PCR in 16 supernatants from 28 subcloned Hs578T co-cultured cells. Betaretrovirus particles were identified by electron microscopy and 17 Integration sites were identified in infected Hs578T cells.
47 integration sites were identified from patients' samples. In patients with $\mathrm{PBC}, 1$ or 2 integration sites were detected in 4 of 5 PBC biliary epithelial samples, 1 of 3 liver samples and 1 to 14 integration sites (median 5) were found in 7 of 10 PBC lymph nodes. Of note, the human betaretrovirus preferentially integrated within genes in $61 \%$ samples. Clustering of 3 or more sites within 15,000 Kb was observed on chromosomes 4, 5, 6, 8 and 11.

\section{Conclusion}

The unequivocal detection of viral integration sites in the human genome and viral isolation studies provide proof that patients with $\mathrm{PBC}$ have infection with a transmissible betaretrovirus. Most PBC patients have evidence of betaretrovirus infection in biliary epithelial cells targeted by the disease process, whereas the perihepatic lymph nodes have the highest viral burden.

\section{References}

I. Xu L, Shen Z, Guo L, Fodera B, Keogh A, Joplin R, O'Donnell B, Aitken J, Carman W, Neuberger J, Mason A: Does a betaretrovirus infection trigger primary biliary cirrhosis? Proc Natl Acad Sci of the USA 2003, 100:8454-8459. 